\title{
Are Aquaporins Expressed in Stomatal Complexes Promising Targets to Enhance Stomatal Dynamics?
}

\author{
Lei Ding and François Chaumont* \\ Louvain Institute of Biomolecular Science and Technology, UCLouvain, Louvain-la-Neuve, Belgium
}

The opening and closure of stomata depend on the turgor pressure adjustment by the influx or efflux of ions and water in guard cells. In this process, aquaporins may play important roles by facilitating the transport of water and other small molecules. In this perspective, we consider the potential roles of aquaporins in the membrane diffusion of different molecules $\left(\mathrm{H}_{2} \mathrm{O}, \mathrm{CO}_{2}\right.$, and $\left.\mathrm{H}_{2} \mathrm{O}_{2}\right)$, processes dependent on abscisic acid and $\mathrm{CO}_{2}$ signaling in guard cells. While the limited data already available emphasizes

\section{OPEN ACCESS}

Edited by:

Rucha Karnik,

University of Glasgow,

United Kingdom

Reviewed by:

Raffaella Balestrini,

Institute for Sustainable Plant

Protection, Italian National Research

Council, Italy

Michael M. Wudick, Heinrich Heine University

of Düsseldorf, Germany

*Correspondence:

François Chaumont

francois.chaumont@uclouvain.be

Specialty section:

This article was submitted to Plant Traffic and Transport,

a section of the journal

Frontiers in Plant Science

Received: 17 January 2020

Accepted: 27 March 2020

Published: 21 April 2020

Citation:

Ding L and Chaumont F (2020)

Are Aquaporins Expressed

in Stomatal Complexes Promising

Targets to Enhance Stomatal

Dynamics? Front. Plant Sci. 11:458.

doi: 10.3389/fpls.2020.00458 the roles of aquaporins in stomatal movement, we propose additional approaches to elucidate the specific roles of single or several aquaporin isoforms in the stomata and evaluate the perspectives aquaporins might offer to improve stomatal dynamics.

Keywords: aquaporin, stomatal movement, signaling, guard cell, membrane diffusion, water, hydrogen peroxide, carbon dioxide

\section{INTRODUCTION}

Stomata are pores formed by two guard cells allowing $\mathrm{CO}_{2}$ uptake for photosynthesis at the expense of water loss by transpiration. While most stomata are formed by two kidney-shaped guard cells, the stomatal complexes of grass consist of two dumbbell-shaped guard cells flanked by two subsidiary cells. The opening and closure of stomata depend on variations in the turgor pressure of the guard cells and, thus, on water and solute fluxes across the cell plasma membrane. Therefore, due to their channel activity and specificity, aquaporins are thought to be involved in stomatal movement. Plant aquaporins cluster in different subfamilies, including the plasma membrane intrinsic proteins (PIPs) and the tonoplast intrinsic proteins (TIPs). In addition to their water channel activity, aquaporins can also facilitate the diffusion of various other small solutes, including $\mathrm{H}_{2} \mathrm{O}_{2}$ and $\mathrm{CO}_{2}$, two important signaling molecules in guard cells. Several aquaporins belonging to the PIP and TIP subfamilies have been reported to be expressed in guard cells or stomatal complexes in various plant species (Chen et al., 2017; Hachez et al., 2017). For instance, PIP aquaporin gene expression was analyzed in maize stomatal complexes isolated by laser microdissection (Heinen et al., 2014). The expression of seven PIP genes accounts for more than $98 \%$ of the total PIP transcripts and the expression of most of them follows a diurnal pattern (Heinen et al., 2014). Diurnal variation in PIP and TIP transcript abundance is also detected in the guard cells of Populus tree using a similar microdissection technique (Durand et al., 2020).

Several papers investigating the physiological role and regulation of the aquaporins expressed in the stomatal complexes have been recently published and the data reviewed by us and colleagues (reviewed in Maurel et al., 2016; Chen et al., 2017; Hachez et al., 2017; Nunes et al., 2019). The aim of this perspective paper is to focus on putative specific roles of aquaporins in stomatal complexes, 
present the future challenge to elucidate them, and evaluate the pertinence to target aquaporins to improve stomatal function.

\section{ASSESSING THE DIRECT OR INDIRECT ROLE OF AQUAPORINS IN STOMATAL CONDUCTANCE}

The role of specific aquaporins in stomatal complexes can be assessed from reverse genetic approaches, either by overexpressing or silencing/knocking out a single gene. In general, deregulating aquaporin expression affects the photosynthesis, the stomatal conductance $\left(g_{s}\right)$, the stomatal movement and/or density, as well as the plant hydraulics (for review, see Maurel et al., 2016; Hachez et al., 2017). As illustrated in Figure $\mathbf{1}$ and Table 1, most of the studies showed an increase in $g_{\mathrm{s}}$ for both monocot and dicot plants overexpressing aquaporin genes, including PIP1, PIP2, and TIP, under control growth condition, while a decrease in $g_{\mathrm{s}}$ was recorded in PIP silenced plants. However, it is important to emphasize that this deregulation of aquaporin gene expression is generally not restricted to the guard cells: most aquaporins are expressed widely throughout the plant and their silencing can affect different tissues. Similarly, the promoters used to overexpress PIP genes are very often constitutive such as the cauliflower mosaic virus $35 S$ promoter or the ubiquitin promoter. The $g_{s}$ is regulated by different mechanisms and signaling events at the whole plant level involving root to shoot communication through hydraulic and chemical signals (Comstock, 2002; Parent et al., 2009; Tardieu et al., 2015) or the photosynthetic apparatus (Lawson et al., 2014; Sade et al., 2014). It is therefore very difficult to determine whether the observed phenotypes are related to altered aquaporin activity within the guard cells themselves or in other root or leaf tissues. This is illustrated by the study of Sade et al. (2014), who showed that the $g_{\mathrm{s}}$ as well as the photosynthetic rate and mesophyll conductance increase in Arabidopsis lines overexpressing NtAQP1 (a PIP isoform) under the control of the $35 \mathrm{~S}$ promoter or the mainly photosynthetic tissue promoter FBPase, but not in lines in which NtAQP1 is expressed under the control of the stomatal-specific promoter KST1 (Sade et al., 2014). This data indicates that aquaporins can indirectly affect the $g_{\mathrm{s}}$ through changes in tissue hydraulic properties probably affecting signaling processes.

In addition, the $g_{s}$ is determined by the stomatal anatomy, including the stomatal density, the size and the pore area (Franks and Beerling, 2009; Faralli et al., 2019), which are potentially influenced by aquaporin expression (Figure 1). The high $g_{s}$ in aquaporin overexpressing lines may be associated with the increase in the stomatal density and/or the stomatal aperture. However, the development of stomata is controlled by complex cellular processes (Chater et al., 2017), and it remains unclear if/how stomatal development/density depends on aquaporins. As shown in Figure 1, the stomatal aperture is increased by overexpressing PIP1 isoforms, while the stomatal density is less affected by the deregulation of PIP1s and/or PIP2s.

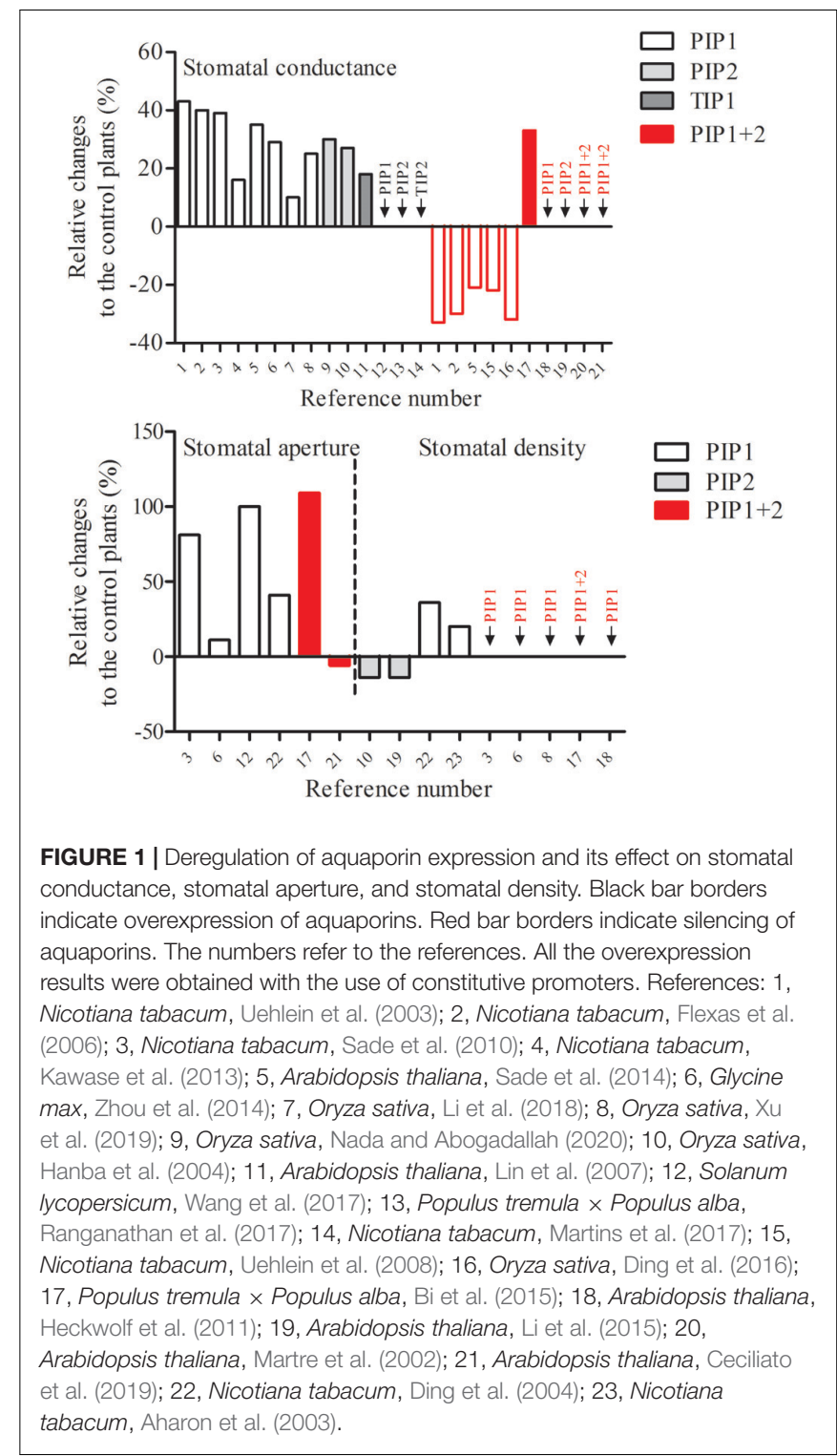

\section{ROLES OF AQUAPORINS EXPRESSED IN THE STOMATAL COMPLEXES}

Ideally, the role of aquaporins expressed in the stomatal complexes has to be determined from plant lines in which aquaporin expression is specifically modified in the guard cells and/or the subsidiary cells. This can be achieved by using cell specific promoters. Similarly, aquaporin silencing through cell type-specific CRISPR-TSKO technology can now be applied (Decaestecker et al., 2019). As mentioned above, Sade et al. (2014) expressed NtAQP1 under the control of the guard cell specific promoter KST1 in Arabidopsis, but did not observe any change in $g_{s}$, even if they did not investigate other stomatal behaviors, including the kinetic of stomatal opening and closure. However, plant lines constitutively deregulated in aquaporin gene expression already available can also constitute a good starting 
TABLE 1 | The relationship between aquaporins and stomatal movement.

\begin{tabular}{|c|c|c|c|c|c|}
\hline Genes & Localization & Species & Regulation & Substrate & References \\
\hline SunTIP7 & Guard cell & Sunflower & Diurnal rhythm of expression & & Sarda et al. (1997) \\
\hline VfPIP1 OE & $\begin{array}{l}\text { Epidermal } \\
\text { peels }\end{array}$ & Arabidopsis & $\begin{array}{l}\text { Stomata closed faster under ABA and dark } \\
\text { treatments }\end{array}$ & & Cui et al. (2008) \\
\hline Atpip2;1 KO & $\begin{array}{l}\text { Epidermal } \\
\text { peels }\end{array}$ & & $\begin{array}{l}\text { Stomata closed slower under ABA treatment, } \\
\text { no difference under }\left[\mathrm{CO}_{2}\right] \text { changing }\end{array}$ & $\mathrm{H}_{2} \mathrm{O}$ and $\mathrm{H}_{2} \mathrm{O}_{2}$ & Grondin et al. (2015) \\
\hline Atpip2;1 KO & $\begin{array}{l}\text { Epidermal } \\
\text { peels }+ \text { intact } \\
\text { leaf }\end{array}$ & & $\begin{array}{l}\text { Stomatal aperture and movement no } \\
\text { differences under }\left[\mathrm{CO}_{2}\right] \text { changing and } \mathrm{ABA} \\
\text { treatments }\end{array}$ & $\mathrm{H}_{2} \mathrm{O}$ and $\mathrm{CO}_{2}$ & Wang et al. (2016) \\
\hline Atpip2;1 KO & $\begin{array}{l}\text { Epidermal } \\
\text { peels }\end{array}$ & & $\begin{array}{l}\text { Stomata closed slower under ABA and flg22 } \\
\text { treatments }\end{array}$ & $\mathrm{H}_{2} \mathrm{O}$ and $\mathrm{H}_{2} \mathrm{O}_{2}$ & Rodrigues et al. (2017) \\
\hline Atpip1;1/pip1;2/pip2;1/pip2;2 KO & $\begin{array}{l}\text { Epidermal } \\
\text { peels }+ \text { intact } \\
\text { leaf }\end{array}$ & & $\begin{array}{l}\text { Stomatal aperture and movement no } \\
\text { differences under ABA treatment }\end{array}$ & & Ceciliato et al. (2019) \\
\hline$Z m P I P s$ & Stomata & Maize & Diurnal rhythm of expression & $\mathrm{H}_{2} \mathrm{O}$ and $\mathrm{CO}_{2}$ & Heinen et al. (2014) \\
\hline ZmPIPs & Intact leaf & & $\begin{array}{l}\text { Expression regulated by }\left[\mathrm{CO}_{2}\right] \text { changing and } \\
\text { carbonic anhydrase activity }\end{array}$ & & Kolbe et al. (2019) \\
\hline MdPIP1;3 OE & Intact leaf & Tomato & Stomata closed faster under drought stress & & Wang et al. (2017) \\
\hline GmPIP1;6 OE & Intact leaf & Soybean & Stomata closed slower under salt stress & & Zhou et al. (2014) \\
\hline PIPS \& TIPS & Stomata & Populus & $\begin{array}{l}\text { Expression regulated by diurnal rhythm and } \\
\text { water stress }\end{array}$ & & Durand et al. (2020) \\
\hline
\end{tabular}

The PIP and TIP isoforms are constitutively expressed under the control of the 35S promoter and silenced by transposon or T-DNA insertion.

material to obtain epidermal peels and follow the stomatal behavior in different conditions. This approach has been recently used to decipher the role and regulation of Arabidopsis PIP aquaporins in guard cells, in relation to the transport of water, $\mathrm{CO}_{2}$ and $\mathrm{H}_{2} \mathrm{O}_{2}$.

\section{Water}

To control the opening and closure of stomata, guard cells have to adjust their volume by up to $\sim 50 \%$ driven by the accumulation and release of solutes, respectively, as well as by the bidirectional transport of water through the plasma membrane and the tonoplast (Jezek and Blatt, 2017). Interestingly, in the grass species having two closely associated lateral subsidiary cells, an inverse behavior of the solute exchanges through the membranes of the subsidiary cells compared with the guard cells controls the opening and closure of the stomata (Chen et al., 2017; Nunes et al., 2019).

Evidence for the involvement of PIP aquaporins in water exchange came from Grondin et al. (2015) and Rodrigues et al. (2017). They showed that the water permeability of wild type guard cell protoplasts is significantly enhanced by abscisic acid (ABA) and the pathogen-associated molecular pattern peptide flg22, which is a well-known molecule inducing stomatal closure, whereas this increase was not observed in guard cells from pip 2;1 KO plants. The closure of stomata observed on peeled epidermis was also reduced in pip2;1 KO lines upon ABA or flg22 incubation (Grondin et al., 2015; Rodrigues et al., 2017). Furthermore ABA treatment activated OST1 kinase, and OST1 phosphorylates Ser-121 of PIP2;1, an event known to activate the water channel activity of PIP aquaporins (Grondin et al., 2015). Altogether, these results suggest that ABA-induced stomatal closure in Arabidopsis is hydraulically controlled by aquaporins, including PIP2;1 and possibly other PIPs and that
PIPs are involved in the stomatal kinetics. However, this data could not be reproduced in an independent study: stomata from pip2;1 KO line retained wild-type like ABA-induced stomatal closure response (Wang et al., 2016). The authors speculated that overlapping aquaporin functions may exist in guard cells since different PIP genes are expressed in Arabidopsis stomata (Zhao et al., 2008). Later on, a quadruple pip1;1, pip1;2, pip2;1, and pip2;2 mutant was generated by the same group, but no significant difference in the decrease in stomatal aperture and $g_{\text {s }}$ upon ABA treatment was observed between the WT and the quadruple mutant (Ceciliato et al., 2019).

Such contradictory results could be explained by different experimental growth conditions or measurement methods. Additional experiments in Arabidopsis or other species are definitely required to confirm or infirm the involvement of specific PIP aquaporins in the dynamic of stomatal movement. This is currently investigated in our laboratory in maize lines deregulated in PIP expression (Ding et al., 2020 and unpublished data).

\section{$\mathrm{CO}_{2}$}

It is well known that high $\mathrm{CO}_{2}$ concentration $\left(\left[\mathrm{CO}_{2}\right]\right)$ and low $\left[\mathrm{CO}_{2}\right]$ induce stomatal closure and opening, respectively (Zhang et al., 2018). As mentioned above, several PIP aquaporins have been shown to facilitate membrane $\mathrm{CO}_{2}$ diffusion. It is the case for the Arabidopsis PIP2;1 when expressed in Xenopus oocytes, suggesting that PIP2;1 facilitates the entry of $\mathrm{CO}_{2}$ into the guard cells to trigger downstream signaling leading to stomatal closure (Wang et al., 2016). PIP2;1 also interacts with the carbonic anhydrase (CA) $\beta C A 4$, and this interaction enables the extracellular $\mathrm{CO}_{2}$ enhancement of the S-type anion channel SLAC1 activity in oocytes, due to the influx of $\mathrm{CO}_{2}$ through PIP2;1 and the production of intracellular $\mathrm{HCO}_{3}{ }^{-}$, 
known as a second messenger activating the SLAC1 activity (Xue et al., 2011; Wang et al., 2016; Zhang et al., 2018). However, no change in $\mathrm{CO}_{2}$ regulation of stomatal movement was observed in pip2;1 mutant compared to the WT, suggesting again that other PIP aquaporins expressed in Arabidopsis guard cells could have similar roles (Wang et al., 2016). In maize, several PIP genes are expressed in stomatal complexes and both PIP1;5 and PIP1;6 are able to increase the membrane $\mathrm{CO}_{2}$ permeability when expressed in yeast (Heinen et al., 2014). The difficulty of gene redundancy could be overcome by specifically targeting the silencing of several PIP genes in guard cells with the CRISPRTSKO technique mentioned above. The expression of PIP genes was analyzed in maize $c a$ mutants growing under high and low $\left[\mathrm{CO}_{2}\right]$ (Kolbe et al., 2019). Interestingly, PIP1;2 and PIP2;5 were up- and down-regulated, respectively, in both WT and calca 2 mutant by a low $\left[\mathrm{CO}_{2}\right]$ treatment. The observation that PIP1;2 expression increases in $c a$ mutants or under low $\left[\mathrm{CO}_{2}\right]$ suggests that PIP1;2 may also act as $\mathrm{CO}_{2}$ membrane facilitator in maize leaves. The fact that these PIP1;2 and PIP2;5 genes do not have a consistent response to $\mathrm{CO}_{2}$ is probably due to different physiological roles, i.e., in controlling $\mathrm{CO}_{2}$ and/or water movement at low $\left[\mathrm{CO}_{2}\right]$. However, this study investigates the expression of PIPs in whole leaves, and it is difficult to distinguish their respective roles in stomatal complexes or other leaf tissues.

\section{$\mathrm{H}_{2} \mathrm{O}_{2}$}

Reactive oxygen species (ROS) play important roles in stomatal closure induced by high $\left[\mathrm{CO}_{2}\right], \mathrm{ABA}$ and biotic stress (Chater et al., 2015; Rodrigues et al., 2017; Sussmilch et al., 2019). $\mathrm{H}_{2} \mathrm{O}_{2}$ is produced in the apoplasm by the activated NADPH oxidases and acts in the guard cells to regulate the activity of $\mathrm{Ca}^{2+}$ channels leading to the activation of SLAC1 in the plasma membrane (Pei et al., 2000). Several aquaporins were previously characterized as $\mathrm{H}_{2} \mathrm{O}_{2}$ channels when expressed in yeast (Bienert et al., 2007, 2014; Bienert and Chaumont, 2014) or reconstituted into liposomes (Wang et al., 2020), or in planta in association with abiotic (Jang et al., 2012; Smirnoff and Arnaud, 2019) and biotic stress (Tian et al., 2016). In Arabidopsis pip2;1 mutant, a lack of ROS $\left(\mathrm{H}_{2} \mathrm{O}_{2}\right)$ accumulation in guard cells, was observed upon $\mathrm{ABA}$ and flg22 treatments (Grondin et al., 2015; Rodrigues et al., 2017), suggesting that PIP aquaporins facilitate the membrane diffusion of $\mathrm{H}_{2} \mathrm{O}_{2}$ to regulate the stomatal movement.

\section{DO AQUAPORINS DIRECTLY OR INDIRECTLY AFFECT CATION TRANSPORT IN STOMATAL COMPLEXES?}

Changes in cell volume depend on the cell osmolality and the addition or the removal of membrane materials. This process in guard cells integrates the membrane traffic with ion transport [reviewed in Jezek and Blatt (2017)]. The soluble $\mathrm{N}$-ethylmaleimide-sensitive factor attachment protein receptor (SNARE) syntaxin SYP121 was shown to regulate the activity of $\mathrm{K}^{+}$channels (Eisenach et al., 2012). In Arabidopsis syp121 mutant, the stomatal reopening following closure in elevated $\left[\mathrm{Ca}^{2+}\right]$ is slower than in WT plants, due to a reduction of the recycling of KAT1 from endosomal membranes. In addition, SYP121 physically interacts with the voltage sensor domain of the $\mathrm{K}^{+}$channels $\mathrm{KC} 1$ and $\mathrm{KAT} 1$, promoting the channel activity. Hence, SYP121 appears as a major regulator of the membrane voltage sensing to coordinate the rate of the secretory traffic with the $\mathrm{K}^{+}$transport (Grefen et al., 2015; Jezek and Blatt, 2017). Interestingly, SYP121 also physically interacts with PIP aquaporins in maize and Arabidopsis (Besserer et al., 2012; Hachez et al., 2014). This interaction is required for the delivery of PIPs to the plasma membrane and might also affect their water channel activity. Mesophyll protoplasts have indeed a lower membrane water permeability in syp121 mutant than in WT plants (Besserer et al., 2012), indicating that SYP121 is necessary for PIPs trafficking to the plasma membrane. It is therefore tempting to speculate that SYP121 controls the trafficking and activity of both $\mathrm{K}^{+}$and water channels in a coordinated way to regulate the cell volume during the stomatal movement. In addition, in other parts of the plants, expression data indicates that $\mathrm{K}^{+}$concentration directly affects the expression of PIP aquaporins, $\mathrm{K}^{+}$starvation reducing their expression while $\mathrm{K}^{+}$resupply increasing the expression (Maathuis et al., 2003; Armengaud et al., 2004). $\mathrm{K}^{+}$channel inhibitors also decreased both water flow and expression of PIP aquaporins (Tazawa et al., 2001; Sahr et al., 2005). Finally, there is still an ancient but still valid hypothesis that PIP aquaporins could serve as turgor sensors in the plasma membrane to modulate the $\mathrm{K}^{+}$ channel activity and cell water homeostasis (Hill et al., 2004; Nongpiur et al., 2020).

Regulation of PIP trafficking appears even more complex. PIPs in higher plants are phylogenetically divided into two groups, PIP1 and PIP2, showing different subcellular localization and activities in protoplasts or when expressed in heterologous systems. While most PIP1s are retained in the endoplasmic reticulum (ER), PIP2s are found in the plasma membrane, but PIP1s and PIP2s can assemble as heterotetramers resulting in co-localization of both proteins in the plasma membrane and an increase in the cell membrane water permeability (Fetter et al., 2004; Berny et al., 2016; Jozefkowicz et al., 2017). In maize stomatal complexes, the proportion of PIP1 transcripts accounts for up to $85 \%$ of the total abundant PIP transcripts, raising the question whether all PIP1s are located in the cell plasma membrane (Heinen et al., 2014). By definition, as PIPs assemble in heterotetramers in all the stoichiometries (Berny et al., 2016), one PIP2 isoform would be enough to direct three PIP1s to the plasma membrane. In this context, the regulation of the subcellular trafficking of PIPs in guard cells and subsidiary cells according to the environmental conditions (day/night, $\mathrm{ABA}$, $\mathrm{CO}_{2}$ ) has to be investigated.

Finally, it was recently reported that Arabidopsis PIP2;1 and PIP2;2 can function as $\mathrm{Na}^{+}$channels in addition to water channels (Byrt et al., 2017; Kourghi et al., 2017). This finding challenges the concept of plant aquaporins as channels of small uncharged solutes. Even though $\mathrm{Na}^{+}$is not the main element in guard cells, it could participate in stomatal control, as suggested in poplars in which the higher $\mathrm{Na}^{+}$amount in 
guard cells of hybrid poplars correlated with higher levels of the vacuolar $\mathrm{Na}^{+}$/proton antiporter NHX1.13 and some PIP and TIP aquaporins (Durand et al., 2020). Whether PIP or TIP aquaporins expressed in stomatal complexes increase permeability to $\mathrm{Na}^{+}$ and directly contribute to the stomatal movement remains to be elucidated.

\section{CONCLUSION}

The expression of several PIP and/or TIP aquaporin genes in stomatal complexes is now well documented (Chen et al., 2017). The constitutive deregulation of aquaporin expression in the whole plant definitely demonstrates the involvement of aquaporins in stomatal conductance, transpiration and photosynthesis, but very limited studies focus on the physiological roles of specific isoform in the guard cells and/or subsidiary cells. Results obtained in Arabidopsis indicate that PIP2;1 aquaporin participates in ABA signaling in guard cells leading to stomatal closure by facilitating $\mathrm{H}_{2} \mathrm{O}_{2}$ entrance and water exit (Grondin et al., 2015; Rodrigues et al., 2017). PIP2;1 is also suggested to be involved in $\mathrm{CO}_{2}$ signaling through its transport and direct interaction with carbonic anhydrase (Wang et al., 2016). These observations indicate that aquaporins could be an important link between the $\mathrm{ABA}$ or $\mathrm{CO}_{2}$ signaling pathway and the cell ROS distribution inducing the stomatal closure. It is interesting to observe that aquaporins act in the kinetics of stomatal closure in Arabidopsis (Grondin et al., 2015) or in maize (Ding and Chaumont, unpublished data). It was recently shown that expression of light-gated $\mathrm{K}^{+}$channel BLINK1 in guard cells accelerates the stomatal aperture and closure, improving carbon assimilation, water use and plant growth (Papanatsiou et al., 2019). Therefore, optimizing the expression and/or activity of aquaporins that affect the kinetics of stomatal closure may represent another interesting way to reach similar favorable phenotypes in crops

\section{REFERENCES}

Aharon, R., Shahak, Y., Wininger, S., Bendov, R., Kapulnik, Y., and Galili, G. (2003). Overexpression of a plasma membrane aquaporin in transgenic tobacco improves plant vigor under favorable growth conditions but not under drought or salt stress. Plant Cell 15, 439-447. doi: 10.1105/tpc.009225

Armengaud, P., Breitling, R., and Amtmann, A. (2004). The potassium-dependent transcriptome of Arabidopsis reveals a prominent role of jasmonic acid in nutrient signaling. Plant Physiol. 136, 2556-2576. doi: 10.1104/pp.104.046482

Berny, M. C., Gilis, D., Rooman, M., and Chaumont, F. (2016). Single mutations in the transmembrane domains of maize plasma membrane aquaporins affect the activity of monomers within a heterotetramer. Mol. Plant 9, 986-1003. doi: 10.1016/j.molp.2016.04.006

Besserer, A., Burnotte, E., Bienert, G. P., Chevalier, A. S., Errachid, A., Grefen, C., et al. (2012). Selective regulation of maize plasma membrane aquaporin trafficking and activity by the SNARE SYP121. Plant Cell 24, 3463-3481. doi: 10.1105/tpc.112.101758

Bi, Z., Merl-Pham, J., Uehlein, N., Zimmer, I., Mühlhans, S., Aichler, M., et al. (2015). RNAi-mediated downregulation of poplar plasma membrane intrinsic proteins (PIPs) changes plasma membrane proteome composition and affects leaf physiology. J. Proteom. 128, 321-332. doi: 10.1016/j.jprot.2015. 07.029 facing ever-changing environmental conditions. To reach this goal, a better understanding of the contribution and regulation (activity, trafficking) of each aquaporin isoform expressed in stomatal complexes is still required, including the TIPs that are located in the tonoplast. This systematic characterization is important to identify the most promising aquaporin isoforms and understand their contribution to the stomatal dynamic behavior in relation to the signaling molecules and, in turn, to improve the water use efficiency.

\section{DATA AVAILABILITY STATEMENT}

The datasets generated for this study are available on request to the corresponding author.

\section{AUTHOR CONTRIBUTIONS}

Both authors contributed to the writing of the manuscript.

\section{FUNDING}

This work was supported by the Belgian National Fund for Scientific Research (FNRS, FRFC 2.4.501.06F), the "Fédération Wallonie-Bruxelles - Actions de Recherches Concertées" (grant ARC16/21-075) and the Pierre and Colette Bauchau Award. LD was supported by an Incoming Post-doc Movein Louvain Fellowship co-funded by the Marie Curie Actions and the ARC grant.

\section{ACKNOWLEDGMENTS}

We apologize to those researchers whose work we have been unable to cite owing to space constraints.

Bienert, G. P., and Chaumont, F. (2014). Aquaporin-facilitated transmembrane diffusion of hydrogen peroxide. Biochim. Biophys. Acta Gen. Subj. 1840, 15961604. doi: 10.1016/j.bbagen.2013.09.017

Bienert, G. P., Heinen, R. B., Berny, M. C., and Chaumont, F. (2014). Maize plasma membrane aquaporin ZmPIP2;5, but not ZmPIP1;2, facilitates transmembrane diffusion of hydrogen peroxide. Biochim. Biophys. Acta Biomemb. 1838, 216-222.

Bienert, G. P., Møller, A. L., Kristiansen, K. A., Schulz, A., Møller, I. M., Schjoerring, J. K., et al. (2007). Specific aquaporins facilitate the diffusion of hydrogen peroxide across membranes. J. Biol. Chem. 282, 1183-1192. doi: 10.1074/jbc. m603761200

Byrt, C. S., Zhao, M., Kourghi, M., Bose, J., Henderson, S. W., Qiu, J., et al. (2017). Non-selective cation channel activity of aquaporin AtPIP2; 1 regulated by $\mathrm{Ca} 2+$ and pH. Plant Cell Environ. 40, 802-815. doi: 10.1111/pce.12832

Ceciliato, P. H., Zhang, J., Liu, Q., Shen, X., Hu, H., Liu, C., et al. (2019). Intact leaf gas exchange provides a robust method for measuring the kinetics of stomatal conductance responses to abscisic acid and other small molecules in Arabidopsis and grasses. Plant Methods 15:38.

Chater, C., Peng, K., Movahedi, M., Dunn, J. A., Walker, H. J., Liang, Y.$\mathrm{K}$., et al. (2015). Elevated CO2-induced responses in stomata require ABA and ABA signaling. Curr. Biol. 25, 2709-2716. doi: 10.1016/j.cub.2015. 09.013 
Chater, C. C., Caine, R. S., Fleming, A. J., and Gray, J. E. (2017). Origins and evolution of stomatal development. Plant Physiol. 174, 624-638. doi: 10.1104/ pp. 17.00183

Chen, Z.-H., Chen, G., Dai, F., Wang, Y., Hills, A., Ruan, Y.-L., et al. (2017). Molecular evolution of grass stomata. Trends Plant Sci. 22, 124-139. doi: 10.1016/j.tplants.2016.09.005

Comstock, J. P. (2002). Hydraulic and chemical signalling in the control of stomatal conductance and transpiration. J. Exp. Bot. 53, 195-200. doi: 10.1093/jexbot/53. 367.195

Cui, X.-H., Hao, F.-S., Chen, H., Chen, J., and Wang, X.-C. (2008). Expression of the Vicia faba VfPIP1 gene in Arabidopsis thaliana plants improves their drought resistance. J. Plant Res. 121, 207-214. doi: 10.1007/s10265-0070130-z

Decaestecker, W., Buono, R. A., Pfeiffer, M. L., Vangheluwe, N., Jourquin, J., Karimi, M., et al. (2019). CRISPR-TSKO: a technique for efficient mutagenesis in specific cell types, tissues, or organs in Arabidopsis. Plant Cell 31, 2868-2887. doi: 10.1105/tpc.19.00454

Ding, L., Gao, L., Liu, W., Wang, M., Gu, M., Ren, B., et al. (2016). Aquaporin plays an important role in mediating chloroplastic $\mathrm{CO} 2$ concentration under high N supply in rice (Oryza sativa) plants. Physiol. Plant. 156, 215-226. doi: $10.1111 /$ ppl.12387

Ding, L., Milhiet, T., Couvreur, V., Nelissen, H., Meziane, A., Parent, B., et al. (2020). Modification of the expression of the aquaporin ZmPIP2;5 affects water relations and plant growth. Plant Physiol. 182, 2154-2165. doi: 10.1104/pp.19. 01183

Ding, X., Iwasaki, I., and Kitagawa, Y. (2004). Overexpression of a lily PIP1 gene in tobacco increased the osmotic water permeability of leaf cells. Plant Cell Environ. 27, 177-186. doi: 10.1046/j.0016-8025.2003.01130.x

Durand, M., Cohen, D., Aubry, N., Buré, C., Tomášková, I., Hummel, I., et al. (2020). Element content and expression of genes of interest in guard cells are connected to spatiotemporal variations in stomatal conductance. Plant Cell Environ. 43, 87-102. doi: 10.1111/pce.13644

Eisenach, C., Chen, Z. H., Grefen, C., and Blatt, M. R. (2012). The trafficking protein SYP121 of Arabidopsis connects programmed stomatal closure and K+ channel activity with vegetative growth. Plant J. 69, 241-251. doi: 10.1111/j. 1365-313x.2011.04786.x

Faralli, M., Matthews, J., and Lawson, T. (2019). Exploiting natural variation and genetic manipulation of stomatal conductance for crop improvement. Curr. Opin. Plant Biol. 49, 1-7. doi: 10.1016/j.pbi.2019.01.003

Fetter, K., Van Wilder, V., Moshelion, M., and Chaumont, F. (2004). Interactions between plasma membrane aquaporins modulate their water channel activity. Plant Cell 16, 215-228. doi: 10.1105/tpc.017194

Flexas, J., Ribas-Carbo, M., Hanson, D. T., Bota, J., Otto, B., Cifre, J., et al. (2006). Tobacco aquaporin NtAQP1 is involved in mesophyll conductance to CO2 in vivo. Plant J. 48, 427-439. doi: 10.1111/j.1365-313x.2006. 02879.x

Franks, P. J., and Beerling, D. J. (2009). Maximum leaf conductance driven by CO2 effects on stomatal size and density over geologic time. Proc. Natl. Acad. Sci. U.S.A. 106, 10343-10347. doi: 10.1073/pnas.0904209106

Grefen, C., Karnik, R., Larson, E., Lefoulon, C., Wang, Y., Waghmare, S., et al. (2015). A vesicle-trafficking protein commandeers $\mathrm{Kv}$ channel voltage sensors for voltage-dependent secretion. Nat. Plants 1:15108.

Grondin, A., Rodrigues, O., Verdoucq, L., Merlot, S., Leonhardt, N., and Maurel, C. (2015). Aquaporins contribute to ABA-triggered stomatal closure through OST1-mediated phosphorylation. Plant Cell 27, 1945-1954. doi: 10.1105/tpc. 15.00421

Hachez, C., Laloux, T., Reinhardt, H., Cavez, D., Degand, H., Grefen, C., et al. (2014). Arabidopsis SNAREs SYP61 and SYP121 coordinate the trafficking of plasma membrane aquaporin PIP2;7 to modulate the cell membrane water permeability. Plant Cell 26, 3132-3147. doi: 10.1105/tpc.114. 127159

Hachez, C., Milhiet, T., Heinen, R. B., and Chaumont, F. (2017). "Roles of aquaporins in stomata," in plant aquaporins: from transport to signalling, in Springer Book Series "Signaling and Communication in Plants, eds F. Chaumont and S. Tyerman (Berlin: Springer-Verlag), 167-183. doi: 10.1007/978-3-31949395-4_8

Hanba, Y. T., Shibasaka, M., Hayashi, Y., Hayakawa, T., Kasamo, K., Terashima, I., et al. (2004). Overexpression of the barley aquaporin HvPIP2;1 increases internal $\mathrm{CO} 2$ conductance and $\mathrm{CO} 2$ assimilation in the leaves of transgenic rice plants. Plant Cell Physiol. 45, 521-529. doi: 10.1093/pcp/pch070

Heckwolf, M., Pater, D., Hanson, D. T., and Kaldenhoff, R. (2011). The Arabidopsis thaliana aquaporin AtPIP1;2 is a physiologically relevant $\mathrm{CO} 2$ transport facilitator. Plant J. 67, 795-804. doi: 10.1111/j.1365-313x.2011.04634.x

Heinen, R. B., Bienert, G. P., Cohen, D., Chevalier, A. S., Uehlein, N., Hachez, C., et al. (2014). Expression and characterization of plasma membrane aquaporins in stomatal complexes of Zea mays. Plant Mol. Biol. 86, 335-350. doi: 10.1007/ s11103-014-0232-7

Hill, A., Shachar-Hill, B., and Shachar-Hill, Y. (2004). What are aquaporins for? J. Memb. Biol. 197, 1-32.

Jang, J. Y., Rhee, J. Y., Chung, G. C., and Kang, H. (2012). Aquaporin as a membrane transporter of hydrogen peroxide in plant response to stresses. Plant Signal. Behav. 7, 1180-1181. doi: 10.4161/psb.21178

Jezek, M., and Blatt, M. R. (2017). The membrane transport system of the guard cell and its integration for stomatal dynamics. Plant Physiol. 174, 487-519. doi: $10.1104 /$ pp. 16.01949

Jozefkowicz, C., Berny, M. C., Chaumont, F., and Alleva, K. (2017). "Heteromerization of plant aquaporins. in "plant aquaporins: from transport to signalling," in Springer Book Series "Signaling and Communication in Plants, eds F. Chaumont and S. Tyerman (Berlin: Springer-Verlag), 29-46. doi: 10.1007/978-3-319-49395-4_2

Kawase, M., Hanba, Y. T., and Katsuhara, M. (2013). The photosynthetic response of tobacco plants overexpressing ice plant aquaporin McMIPB to a soil water deficit and high vapor pressure deficit. J. Plant Res. 126, 517-527. doi: 10.1007/ s10265-013-0548-4

Kolbe, A. R., Studer, A. J., Cornejo, O. E., and Cousins, A. B. (2019). Insights from transcriptome profiling on the non-photosynthetic and stomatal signaling response of maize carbonic anhydrase mutants to low $\mathrm{CO} 2$. BMC Genomics 20:138. doi: 10.1186/s12864-019-5522-7

Kourghi, M., Nourmohammadi, S., Pei, J., Qiu, J., Mcgaughey, S., Tyerman, S., et al. (2017). Divalent cations regulate the ion conductance properties of diverse classes of aquaporins. Intern. J. Mol. Sci. 18:2323. doi: 10.3390/ijms18112323

Lawson, T., Simkin, A. J., Kelly, G., and Granot, D. (2014). Mesophyll photosynthesis and guard cell metabolism impacts on stomatal behaviour. New Phytol. 203, 1064-1081. doi: 10.1111/nph.12945

Li, J., Yu, G., Sun, X., Liu, Y., Liu, J., Zhang, X., et al. (2015). AcPIP2, a plasma membrane intrinsic protein from halophyte Atriplex canescens, enhances plant growth rate and abiotic stress tolerance when overexpressed in Arabidopsis thaliana. Plant Cell Rep. 34, 1401-1415. doi: 10.1007/s00299-015-1796-7

Li, W., Qiang, X. J., Han, X. R., Jiang, L. L., Zhang, S. H., Han, J., et al. (2018). Ectopic expression of a Thellungiella salsuginea aquaporin gene, TsPIP1;1, increased the salt tolerance of rice. Intern. J. Mol. Sci. 19:2229. doi: 10.3390/ ijms19082229

Lin, W., Peng, Y., Li, G., Arora, R., Tang, Z., Su, W., et al. (2007). Isolation and functional characterization of PgTIP1, a hormone-autotrophic cells-specific tonoplast aquaporin in ginseng. J. Exp. Bot. 58, 947-956. doi: 10.1093/jxb/ erl255

Maathuis, F. J., Filatov, V., Herzyk, P., Krijger, C., Axelsen, K., Chen, S., et al. (2003). Transcriptome analysis of root transporters reveals participation of multiple gene families in the response to cation stress. Plant J. 35, 675-692. doi: 10.1046/j.1365-313x.2003.01839.x

Martins, C. P., Neves, D. M., Cidade, L. C., Mendes, A. F., Silva, D. C., Almeida, A.-A. F., et al. (2017). Expression of the citrus CsTIP2; 1 gene improves tobacco plant growth, antioxidant capacity and physiological adaptation under stress conditions. Planta 245, 951-963.

Martre, P., Morillon, R., Barrieu, F., North, G. B., Nobel, P. S., and Chrispeels, M. J. (2002). Plasma membrane aquaporins play a significant role during recovery from water deficit. Plant Physiol. 130, 2101-2110. doi: 10.1104/pp. 009019

Maurel, C., Verdoucq, L., and Rodrigues, O. (2016). Aquaporins and plant transpiration. Plant Cell Environ. 39, 2580-2587. doi: 10.1111/pce.12814

Nada, R. M., and Abogadallah, G. M. (2020). Contrasting root traits and native regulation of aquaporin differentially determine the outcome of overexpressing a single aquaporin (OsPIP2; 4) in two rice cultivars. Protoplasma 257, 583-595. doi: 10.1007/s00709-019-01468-x

Nongpiur, R. C., Singla-Pareek, S. L., and Pareek, A. (2020). The quest for osmosensors in plants. J. Exp. Bot. 71, 595-607. doi: 10.1093/jxb/erz263 
Nunes, T. D., Zhang, D., and Raissig, M. T. (2019). Form, development and function of grass stomata. Plant J. 101, 780-799. doi: 10.1111/tpj.14552

Papanatsiou, M., Petersen, J., Henderson, L., Wang, Y., Christie, J., and Blatt, M. (2019). Optogenetic manipulation of stomatal kinetics improves carbon assimilation, water use, and growth. Science 363, 1456-1459. doi: 10.1126/ science.aaw0046

Parent, B., Hachez, C., Redondo, E., Simonneau, T., Chaumont, F., and Tardieu, F. (2009). Drought and abscisic acid effects on aquaporin content translate into changes in hydraulic conductivity and leaf growth rate: a trans-scale approach. Plant Physiol. 149, 2000-2012. doi: 10.1104/pp.108.130682

Pei, Z.-M., Murata, Y., Benning, G., Thomine, S., Klüsener, B., Allen, G. J., et al. (2000). Calcium channels activated by hydrogen peroxide mediate abscisic acid signalling in guard cells. Nature 406:731. doi: 10.1038/35021067

Ranganathan, K., Cooke, J. E., El Kayal, W., Equiza, M. A., Vaziriyeganeh, M., and Zwiazek, J. J. (2017). Over-expression of PIP2;5 aquaporin alleviates gas exchange and growth inhibition in poplars exposed to mild osmotic stress with polyethylene glycol. Acta Physiol. Plant. 39:187.

Rodrigues, O., Reshetnyak, G., Grondin, A., Saijo, Y., Leonhardt, N., Maurel, C., et al. (2017). Aquaporins facilitate hydrogen peroxide entry into guard cells to mediate ABA-and pathogen-triggered stomatal closure. Proc. Natl. Acad. Sci. U.S.A. 114, 9200-9205. doi: 10.1073/pnas.1704754114

Sade, N., Gallé, A., Flexas, J., Lerner, S., Peleg, G., Yaaran, A., et al. (2014). Differential tissue-specific expression of NtAQP1 in Arabidopsis thaliana reveals a role for this protein in stomatal and mesophyll conductance of $\mathrm{CO}$ 2 under standard and salt-stress conditions. Planta 239, 357-366. doi: 10.1007/ s00425-013-1988-8

Sade, N., Gebretsadik, M., Seligmann, R., Schwartz, A., Wallach, R., and Moshelion, M. (2010). The role of tobacco Aquaporin1 in improving water use efficiency, hydraulic conductivity, and yield production under salt stress. Plant Physiol. 152, 245-254. doi: 10.1104/pp.109.145854

Sahr, T., Voigt, G., Paretzke, H. G., Schramel, P., and Ernst, D. (2005). Caesiumaffected gene expression in Arabidopsis thaliana. New Phytol. 165, 747-754. doi: 10.1111/j.1469-8137.2004.01282.x

Sarda, X., Tousch, D., Ferrare, K., Legrand, E., Dupuis, J., Casse-Delbart, F., et al. (1997). Two TIP-like genes encoding aquaporins are expressed in sunflower guard cells. Plant J. 12, 1103-1111. doi: 10.1046/j.1365-313x.1997.12051103.x

Smirnoff, N., and Arnaud, D. (2019). Hydrogen peroxide metabolism and functions in plants. New Phytol. 221, 1197-1214. doi: 10.1111/nph.15488

Sussmilch, F. C., Schultz, J., Hedrich, R., and Roelfsema, M. R. G. (2019). Acquiring control: the evolution of stomatal signalling pathways. Trends Plant Sci. 24, 342-351. doi: 10.1016/j.tplants.2019.01.002

Tardieu, F., Simonneau, T., and Parent, B. (2015). Modelling the coordination of the controls of stomatal aperture, transpiration, leaf growth, and abscisic acid: update and extension of the tardieu-davies model. J. Exp. Bot. 66, 2227-2237. doi: $10.1093 /$ jxb/erv039

Tazawa, M., Sutou, E., and Shibasaka, M. (2001). Onion root water transport sensitive to water channel and $\mathrm{K}+$ channel inhibitors. Plant Cell Physiol. 42, 28-36. doi: 10.1093/pcp/pce004

Tian, S., Wang, X., Li, P., Wang, H., Ji, H., Xie, J., et al. (2016). Plant aquaporin AtPIP1;4 links apoplastic $\mathrm{H} 2 \mathrm{O} 2$ induction to disease immunity pathways. Plant Physiol. 171, 1635-1650.
Uehlein, N., Lovisolo, C., Siefritz, F., and Kaldenhoff, R. (2003). The tobacco aquaporin NtAQP1 is a membrane CO2 pore with physiological functions. Nature 425, 734-737. doi: 10.1038/nature0 2027

Uehlein, N., Otto, B., Hanson, D. T., Fischer, M., Mcdowell, N., and Kaldenhoff, R. (2008). Function of Nicotiana tabacum aquaporins as chloroplast gas pores challenges the concept of membrane CO2 permeability. Plant Cell 20, 648-657. doi: 10.1105/tpc.107.054023

Wang, C., Hu, H., Qin, X., Zeise, B., Xu, D., Rappel, W.-J., et al. (2016). Reconstitution of $\mathrm{CO} 2$ regulation of SLAC1 anion channel and function of CO2-permeable PIP2;1 aquaporin as CARBONIC ANHYDRASE4 interactor. Plant Cell 28, 568-582. doi: 10.1105/tpc.15.00637

Wang, H., Schoebel, S., Schmitz, F., Dong, H., and Hedfalk, K. (2020). Characterization of aquaporin-driven hydrogen peroxide transport. Biochim. Biophys. Acta Biomembr. 1862:183065. doi: 10.1016/j.bbamem.2019. 183065

Wang, L., Li, Q.-T., Lei, Q., Feng, C., Zheng, X., Zhou, F., et al. (2017). Ectopically expressing MdPIP1;3, an aquaporin gene, increased fruit size and enhanced drought tolerance of transgenic tomatoes. BMC Plant Biol. 17:246. doi: 10.1186/ s12870-017-1212-2

Xu, F., Wang, K., Yuan, W., Xu, W., Liu, S., Kronzucker, H. J., et al. (2019). Overexpression of rice aquaporin OsPIP1;2 improves yield by enhancing mesophyll CO2 conductance and phloem sucrose transport. J. Exp. Bot. 70, 671-681. doi: 10.1093/jxb/ery386

Xue, S., Hu, H., Ries, A., Merilo, E., Kollist, H., and Schroeder, J. I. (2011). Central functions of bicarbonate in S-type anion channel activation and OST1 protein kinase in CO2 signal transduction in guard cell. EMBO J. 30, 1645-1658. doi: 10.1038/emboj.2011.68

Zhang, J., De-Oliveira-Ceciliato, P., Takahashi, Y., Schulze, S., Dubeaux, G., Hauser, F., et al. (2018). Insights into the molecular mechanisms of CO2-mediated regulation of stomatal movements. Curr. Biol. 28, R1356-R1363.

Zhao, Z., Zhang, W., Stanley, B. A., and Assmann, S. M. (2008). Functional proteomics of Arabidopsis thaliana guard cells uncovers new stomatal signaling pathways. Plant Cell 20, 3210-3226. doi: 10.1105/tpc.108. 063263

Zhou, L., Wang, C., Liu, R., Han, Q., Vandeleur, R. K., Du, J., et al. (2014). Constitutive overexpression of soybean plasma membrane intrinsic protein GmPIP1;6 confers salt tolerance. BMC Plant Biol. 14:181. doi: 10.1186/14712229-14- 181

Conflict of Interest: The authors declare that the research was conducted in the absence of any commercial or financial relationships that could be construed as a potential conflict of interest.

Copyright (c) 2020 Ding and Chaumont. This is an open-access article distributed under the terms of the Creative Commons Attribution License (CC BY). The use, distribution or reproduction in other forums is permitted, provided the original author(s) and the copyright owner(s) are credited and that the original publication in this journal is cited, in accordance with accepted academic practice. No use, distribution or reproduction is permitted which does not comply with these terms. 